\title{
Fenton-Like Oxidation of Malachite Green Solutions: Kinetic and Thermodynamic Study
}

\author{
Saeedeh Hashemian \\ Chemistry Department, Islamic Azad University, Yazd Branch, P. O. Box 89195/155, Yazd, Iran \\ Correspondence should be addressed to Saeedeh Hashemian; sa_hashemian@yahoo.com
}

Received 25 May 2013; Revised 19 June 2013; Accepted 25 June 2013

Academic Editor: Oleksandr A. Loboda

Copyright (C) 2013 Saeedeh Hashemian. This is an open access article distributed under the Creative Commons Attribution License, which permits unrestricted use, distribution, and reproduction in any medium, provided the original work is properly cited.

\begin{abstract}
Oxidation by Fenton-like $\left(\mathrm{Fe}^{3+} / \mathrm{H}_{2} \mathrm{O}_{2}\right)$ reactions is proven to be an economically feasible process for destruction of a variety of hazardous pollutants in wastewater. In this study, the degradation and mineralization of malachite green dye are reported using Fenton-like reaction. The effects of different parameters like $\mathrm{pH}$ of the solution, the initial concentrations of $\mathrm{Fe}^{3+}, \mathrm{H}_{2} \mathrm{O}_{2}$, and dye, temperature, and added electrolytes $\left(\mathrm{Cl}^{-}\right.$and $\left.\mathrm{SO}_{4}{ }^{2-}\right)$ on the oxidation of the dye were investigated. Optimized condition was determined. The efficiency of $95.5 \%$ degradation of MAG after 15 minutes of reaction at $\mathrm{pH} 3$ was obtained. TOC removal indicates partial and insignificant mineralization of malachite green dye. The results of experiments showed that degradation of malachite green dye in Fenton-like oxidation process can be described with a pseudo-second-order kinetic model. The thermodynamic constants of the Fenton oxidation process were evaluated. The results implied that the oxidation process was feasible, spontaneous, and endothermic. The results will be useful for designing the treatment systems of various dye-containing wastewaters.
\end{abstract}

\section{Introduction}

Dyes in wastewater are of particular environmental concern since they not only give an undesirable color to the waters but also in some cases are harmful compounds and can originate dangerous by-products through oxidation, hydrolysis, or other chemical reactions taking place in the waste phase. Environmental research has paid special attention to dye compounds because of the extensive environmental contamination arising from dyeing operations. Various attempts have been made for the removal of dyes from water and wastewater. There are several methods applicable for the reclamation of dyeing wastewaters $[1,2]$. Commonly applied treatment methods for color removal from dye-contaminated effluents consist of various processes involving biological, physical and chemical decolorization methods. The biological treatment is not a complete solution to the problem due to biological resistance of some dyes [3]. The traditional treatment techniques were applied in wastewaters, such as ozonation [4], membrane [5], oxidation [6,7], photochemical [8], and adsorption [9-13]. Various Fenton processes were used for oxidation of dyes. Homogenous Fenton reaction $\left(\mathrm{Fe}^{2+} / \mathrm{H}_{2} \mathrm{O}_{2}\right)$ is one of the most important processes to generate hydroxyl radicals ${ }^{\circ} \mathrm{OH}$ [14-16]. These processes are involved in the generation of highly reactive radicals (especially hydroxyl radicals) in enough quantity to affect water purification, and their use is justified by the low organic content of the wastewaters to be treated. They have low reaction temperatures and thus require the presence of very active oxidation agents. In particular, the oxidation using Fenton's reagent has proved to be a promising and attractive treatment method for the effective destruction of a large number of hazardous and organic pollutants [17-21].

The Fenton process completely destroys contaminants and breaks them down into harmless compounds, such as carbon dioxide, water, and inorganic salts. However, its applications are limited due to the generation of excessive amounts of ferric hydroxide sludge that requires additional separation process and disposal [22].

Malachite green is classified in the dyestuff industry as a triarylmethane dye. Malachite green (MAG) is usually used as a dye for materials such as silk, leather, and paper. Removal of malachite green by different methods such as oxidation [23], catalytic oxidation [24], electrooxidation [25], and adsorption by agro-industry waste [26], peel [27], and solid agricultural waste $[28,29]$ was studied. 
Fenton's reagent is a mixture of ferrous ion and hydrogen peroxide generating hydroxyl radical $\left({ }^{\circ} \mathrm{OH}\right)$ in situ according to the following equation:

$$
\mathrm{Fe}^{2+}+\mathrm{H}_{2} \mathrm{O}_{2} \longrightarrow \mathrm{Fe}^{3+}+\mathrm{OH}^{-}+{ }^{\cdot} \mathrm{OH}
$$

$\mathrm{Fe}(\mathrm{III})$ can catalyze the decomposition of $\mathrm{H}_{2} \mathrm{O}_{2}$. The reaction of $\mathrm{H}_{2} \mathrm{O}_{2}$ with $\mathrm{Fe}^{3+}$ (the so-called Fenton's-like reagent) goes through the formation of hydroperoxyl radical $\mathrm{HO}_{2} \cdot[30]:$

$$
\begin{gathered}
\mathrm{Fe}^{3+}+\mathrm{H}_{2} \mathrm{O}_{2} \longrightarrow \mathrm{Fe}^{2+}+\mathrm{HO}_{2}{ }^{\cdot}+\mathrm{H}^{+} \\
\mathrm{Fe}^{3+}+\mathrm{HO}_{2} \cdot \mathrm{Fe}^{2+}+\mathrm{H}^{+}+\mathrm{O}_{2} \\
\mathrm{Fe}^{2+}+{ }^{\cdot} \mathrm{OH} \longrightarrow \mathrm{Fe}^{3+}+{ }^{-} \mathrm{OH} \\
\cdot \mathrm{OH}+\mathrm{H}_{2} \mathrm{O}_{2} \longrightarrow \mathrm{HO}_{2}^{\cdot}+\mathrm{H}_{2} \mathrm{O} \\
\mathrm{Fe}^{2+}+\mathrm{HO}_{2} \cdot \mathrm{Fe}^{3+}+\mathrm{HO}_{2}^{-} \\
\cdot \mathrm{OH}+\mathrm{HO}^{\cdot} \longrightarrow \mathrm{H}_{2} \mathrm{O}_{2}
\end{gathered}
$$

The specific objectives of this study are the investigation of removal efficiencies of malachite green (MAG) by Fenton-like process. Important variables such as oxidation time, effect of $\mathrm{pH}$, dosages of $\mathrm{H}_{2} \mathrm{O}_{2}$, and ferrous ions were examined. The kinetics and thermodynamic of process also were determined.

\section{Experimental}

2.1. Material and Methods. The basic dye, MAG, has molecular formula $\mathrm{C}_{23} \mathrm{H}_{25} \mathrm{ClN}_{2}$ and molar mass $364.911 \mathrm{~g} / \mathrm{mol}$ with $\lambda_{\max } 620 \mathrm{~nm}$ and was used as received without further purification to prepare simulated wastewater. $5.0 \times$ $10^{-3}$ stock solution of MAG was prepared, and working solutions are prepared by the dilution. Experimental solutions of the desired concentration were obtained by successive dilutions. The chemical structure of malachite green (4-[(4-dimethylaminophenyl)phenyl-methyl]$\mathrm{N}, \mathrm{N}$-dimethylaniline) is shown in Figure 1.

All the reagents used in the experiments were in analytical grade (Merck) and were used without further purification. All the experiments were conducted at room temperature. The dye oxidation was achieved by Fenton-like reagent which was composed of a mixture of $\mathrm{Fe}_{2}\left(\mathrm{SO}_{4}\right)_{3} \cdot 7 \mathrm{H}_{2} \mathrm{O}$ and $\mathrm{H}_{2} \mathrm{O}_{2}$ (30\%). The necessary quantities of $\mathrm{Fe}^{3+}$ and $\mathrm{H}_{2} \mathrm{O}_{2}$ were added simultaneously in the dye solution. All experiments were conducted in a $500 \mathrm{~mL}$ thermostated batch glass reactor equipped with the magnetic stirrer. The kinetics of oxidation was followed by taking samples at regular time interval.

The residual concentration of the MAG in the solution at different times of sampling was determined. The residual concentration of the dye was deducted from the calibration curves which were produced at wavelength corresponding to the maximum of absorbance $(620 \mathrm{~nm})$ on an UV-visible spectrophotometer apparatus (Shimadzu $160 \mathrm{~A}$ ). The cells used were in quartz $1 \mathrm{~cm}$ thick. The discoloration efficiency

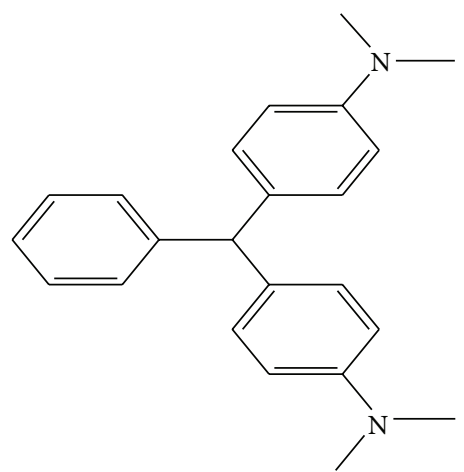

Figure 1: Chemical structure of malachite green (MAG).

of the dye $(\mathrm{X})$ with respect to its initial concentration is calculated as

$$
\% \mathrm{X}=\left([\mathrm{MAG}]_{0}-[\mathrm{MAG}] /[\mathrm{MAG}]_{0}\right) \times 100,
$$

where $[\mathrm{MAG}]_{0}$ and $[\mathrm{MAG}]$ are the initial and appropriate concentrations of dye at any reaction time $t$, respectively.

\section{Results and Discussion}

3.1. Effect of $\mathrm{pH}$ on Decolorization. $\mathrm{pH}$ has a major effect on the efficiency of MAG treatment. The oxidation was done for 120 min under controlled $\mathrm{pH}$ condition with constant dose of $\mathrm{Fe}^{3+}\left(1.0 \times 10^{-4} \mathrm{M}\right)$ and $\mathrm{H}_{2} \mathrm{O}_{2}\left(5 \times 10^{-2} \mathrm{M}\right)$. The effect of $\mathrm{pH}$ on the removal of malachite green using $50 \mathrm{mg} \mathrm{L}^{-1}$ of dye was studied. The oxidation of MAG as a function of $\mathrm{pH}$ is shown in Figure 2. It is evident that change in the $\mathrm{pH}$ of the solution to Fenton-like value of 3 leads to increases in the extent of MAG oxidation. It is apparent from that extent of decolorization decreases with increase in $\mathrm{pH}$, and at $\mathrm{pH} 3.0$ almost $>95 \%$ color removal was observed. Therefore, the results demonstrate that the $\mathrm{pH}$ value for the most effective oxidation of MAG is approximately 3. The decrease in oxidation rate at $\mathrm{pH}>3$ could be explained by the formation of $\mathrm{Fe}(\mathrm{OH})_{3}$, which has lower catalytic activity in the decomposition of $\mathrm{H}_{2} \mathrm{O}_{2}$ [30]. The low activity detected for high $\mathrm{pH}$ has been reported, and the results closely agreed with those in the literature [19, 30-32].

3.2. Effect of $\mathrm{Fe}^{3+}$ Ferrous Dosage. The concentration of $\mathrm{Fe}^{3+}$ is one of the critical parameters in Fenton processes. In the present study, the influence of different iron concentrations $\left(\mathrm{Fe}^{3+}=1.0 \times 10^{-6}-1.0 \times 10^{-3} \mathrm{M}\right)$ expressed as MAG removal is illustrated in Figure 3 . The concentration of hydrogen peroxide is fixed as $0.05 \mathrm{M}$, and MAG concentration is $3.0 \times 10^{-5} \mathrm{M}$. It can be seen from results that MAG degradation increased with increasing $\mathrm{Fe}^{+3}$ concentrations. This is due to the fact that $\mathrm{Fe}^{+3}$ plays a very important role in the decompositions of $\mathrm{H}_{2} \mathrm{O}_{2}$ to generate the ${ }^{\circ} \mathrm{OH}$ in the Fenton process. The lower degradation capacity of $\mathrm{Fe}^{3+}$ at small concentration is probably due to the lowest ${ }^{\circ} \mathrm{OH}$ radicals producing a variable for oxidation $[16,19]$, for higher concentration of $\mathrm{Fe}^{+3}$ oxidation of dye will decrease. This can be explained by 


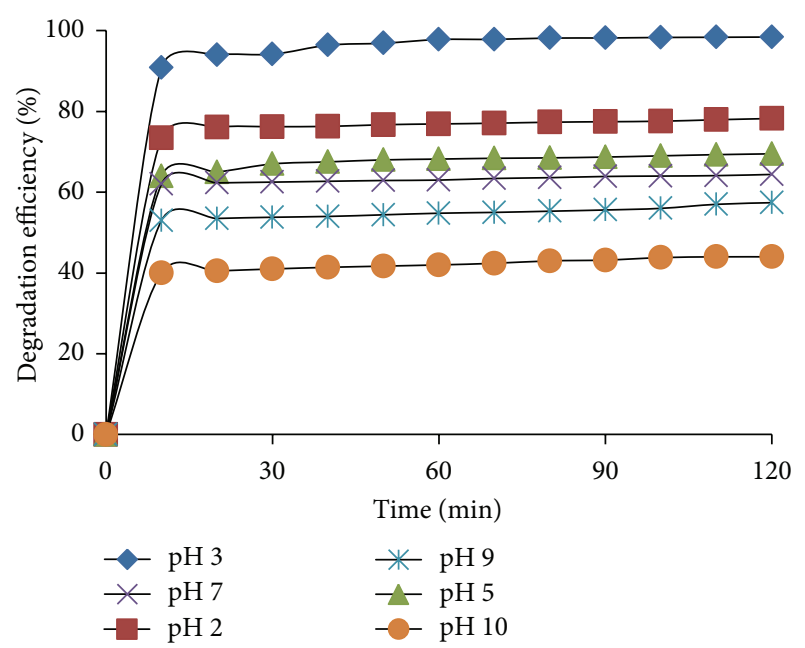

Figure 2: Effect of $\mathrm{pH}$ on the discoloration efficiency for Fentonlike oxidation process, $\left(\left[\mathrm{Fe}^{3+}\right]=1.0 \times 10^{-4} \mathrm{M},\left[\mathrm{H}_{2} \mathrm{O}_{2}\right]=5.0 \times 10^{-2} \mathrm{M}\right.$, $\left.[\mathrm{MAG}]=3.0 \times 10^{-5} \mathrm{M}\right)$.

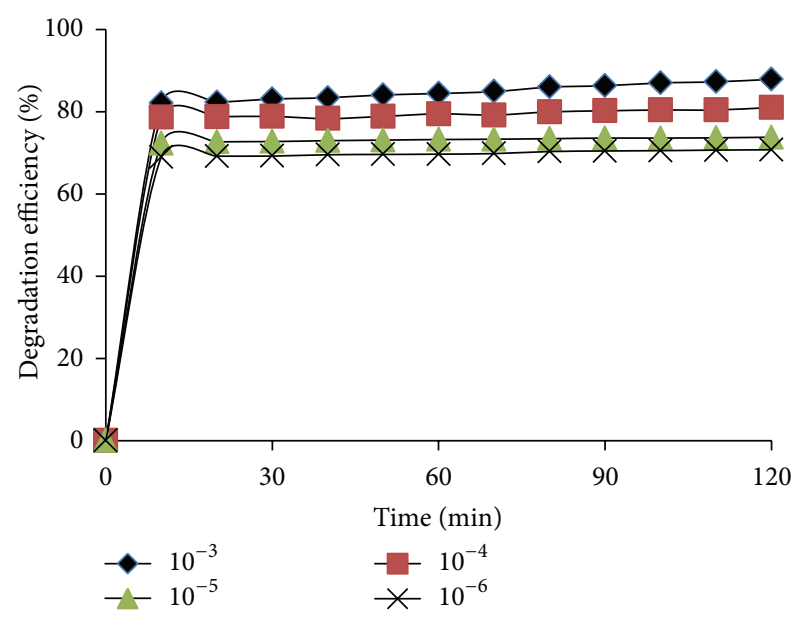

FIGURE 3: Effect of $\mathrm{Fe}^{3+}$ concentration on the discoloration efficiency for Fenton-like oxidation process, $\left(\left[\mathrm{H}_{2} \mathrm{O}_{2}\right]=5.0 \times 10^{-2},[\mathrm{MAG}]=3.0\right.$ $\left.\times 10^{-5} \mathrm{M}\right)$.

the fact that, when the concentrations of $\mathrm{Fe}^{3+}$ are high, can react with the $\mathrm{HO}_{2}{ }^{\circ}$ and finally reduce consumed the very reactive ${ }^{\circ} \mathrm{OH}$ radical according to (3).

3.3. Effect of $\mathrm{H}_{2} \mathrm{O}_{2}$ Concentration. $\mathrm{H}_{2} \mathrm{O}_{2}$ plays the role of an oxidizing agent in this process. The selection of an optimal $\mathrm{H}_{2} \mathrm{O}_{2}$ concentration for the decolorization of MAG is important from practical point of view due to the cost of $\mathrm{H}_{2} \mathrm{O}_{2}$ [33].

Oxidation of dyes by Fenton and Fenton-like process is carried out by ${ }^{\circ} \mathrm{OH}$ radicals that are directly produced from the reaction between $\mathrm{H}_{2} \mathrm{O}_{2}, \mathrm{Fe}^{2+}$, and $\mathrm{Fe}^{3+}$. To determine the concentration of $\mathrm{H}_{2} \mathrm{O}_{2}$ giving the maximum $\mathrm{MAG}$ discoloration efficiency, experiments were conducted, and results detained are represented in Figure 4. The discoloration efficiency according to time for different concentrations of

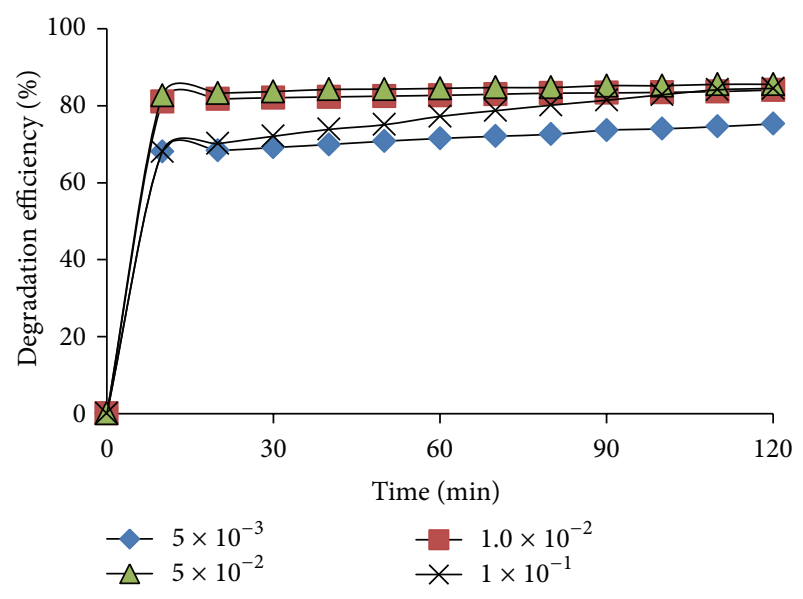

FIGURE 4: Effect of $\mathrm{H}_{2} \mathrm{O}_{2}$ concentration on the discoloration efficiency for Fenton-like oxidation process $\left([\mathrm{MAG}]=3.0 \times 10^{-5} \mathrm{M}\right.$, $\left.\left.\left[\mathrm{Fe}^{+3}\right]=1.0 \times 10^{-4}\right]\right)$.

$\mathrm{H}_{2} \mathrm{O}_{2}$ shows that the dye degradation yield increases with increasing concentration of $\mathrm{H}_{2} \mathrm{O}_{2}$. For the oxidation process, the addition of $\mathrm{H}_{2} \mathrm{O}_{2}$ from $5.0 \times 10^{-3}-1.0 \times 10^{-1} \mathrm{M}$ increases the decolorization from 68 to $95 \%$ at $10 \mathrm{~min}$. The increase in the decolorization is due to the increase in hydroxyl radical concentration by addition of $\mathrm{H}_{2} \mathrm{O}_{2}$ [17]. However at higher $\mathrm{H}_{2} \mathrm{O}_{2}$ concentration, efficiency of dye removal showed no significant efficiency, which is due to recombination of hydroxyl radicals, and scavenging the $\mathrm{OH}$ radicals will occur, which can be expressed by (2), (5), and (6).

3.4. Effect of Relation $\left[\mathrm{Fe}^{3+}\right] /\left[\mathrm{H}_{2} \mathrm{O}_{2}\right]$. The main process variables affecting the rate of a Fenton-like reaction are the molar concentrations of the oxidant $\left(\mathrm{H}_{2} \mathrm{O}_{2}\right)$ and catalyst $\left(\mathrm{Fe}^{3+}\right)$, particularly the $\mathrm{Fe}^{3+}: \mathrm{H}_{2} \mathrm{O}_{2}$ molar ratio. Therefore, color removal as a function of the initial molar ratio of $\mathrm{Fe}^{3+} / \mathrm{H}_{2} \mathrm{O}_{2}$ was investigated. The different ratios of $\left[\mathrm{Fe}^{3+}\right] /\left[\mathrm{H}_{2} \mathrm{O}_{2}\right] 1-400$ are reported from the literature. The experimental results showed that the optimum $\mathrm{Fe}^{3+}: \mathrm{H}_{2} \mathrm{O}_{2}$ molar ratio for the removal of MAG was 1:50 [19, 34]. The reaction of $\mathrm{Fe}^{3+}$ with $\mathrm{H}_{2} \mathrm{O}_{2}$ leads to the formation of $\mathrm{Fe}^{2+}$ ions, which can further react with $\mathrm{H}_{2} \mathrm{O}_{2}$ to produce $\mathrm{OH}$ radical. Therefore, a low $\mathrm{Fe}^{3+}$ concentration decreases MAG degradation. MAG removal actually ceased when the $\mathrm{Fe}^{3+}: \mathrm{H}_{2} \mathrm{O}_{2}$ molar ratio increased from 1:50 to 1:500 for $1 \mathrm{mM} \mathrm{Fe}^{3+}$, indicating that $\mathrm{H}_{2} \mathrm{O}_{2}$ was overdosed when its concentration rose tenfold. In the presence of $50 \mathrm{mM}$ of $\mathrm{H}_{2} \mathrm{O}_{2}$, the ionic liquid is probably eliminated solely by the reaction with ${ }^{\circ} \mathrm{OH}$, but at $500 \mathrm{mM}$; as it is expected, most of the $\mathrm{H}_{2} \mathrm{O}_{2}$ dosage applied was consumed in the first stage of the fast reaction. The oxidation of ionic liquids was done not only by reaction with ${ }^{\circ} \mathrm{OH}$ radicals but also by other radical species generated in vigorous $\mathrm{Fe}^{+3} / \mathrm{H}_{2} \mathrm{O}_{2}$ reactions such $\mathrm{FeO}^{3+}$ [35] and $\mathrm{Fe}^{3+} \mathrm{HO}_{2}{ }^{2+}$ [30] which then decrease.

3.5. Effect of Dye Concentration. The efficiency of the Fentonlike process as a function of initial concentration of dye was 
evaluated. Figure 5 shows the changes of MAG concentration with the reaction time. The results indicated that decolorization efficiency increased when the initial dye concentration increased. Concentration plays a very important role in reactions according to the collision theory of chemical reactions. Two reactants were in a closed container. All the molecules contained within are colliding constantly. By increasing the concentration of one or more reactants, the frequency of collisions between reactant molecules is increased, and the frequency of effective collisions that causes a reaction to occur will also be high. The lifetime of hydroxyl radicals is very short (only a few nanoseconds), and they can only react where they are formed; therefore, as increasing the quantity of dye molecules per volume unit logically enhances the probability of collision between organic matter and oxidizing species, leading to an increase in the decolorization efficiency [36].

3.6. Effect of Temperature. The influence of reaction temperature on the decolorization efficiency of MAG was investigated by varying temperature from $20^{\circ} \mathrm{C}$ to $70^{\circ} \mathrm{C}$. Temperature is critical to the reaction rate, product yield, and distribution. The result is illustrated in Figure 6. It can be seen that raising the temperature has a positive impact on the decolorization of MAG. The decolorization efficiency within 10 min reaction increased from $78 \%$ to $95 \%$ as the different temperatures. This is due to the fact that higher temperature increased the reaction rate between hydrogen peroxide and the catalyst, thus increasing the rate of generation of oxidizing species such as ${ }^{\circ} \mathrm{OH}$ radical or high-valence iron species [34]. In addition, a higher temperature can provide more energy for the reactant molecules to overcome reaction activation energy [37]. Although the decolorization efficiency for $T=$ $30^{\circ} \mathrm{C}$ is lower than those obtained at $T=40^{\circ} \mathrm{C}$, the values of dyes removal achieved at $30^{\circ} \mathrm{C}$ might be considered satisfactory. At higher temperature, the efficiency of MAG oxidation decreases. This phenomenon may be due to the decomposition of $\mathrm{H}_{2} \mathrm{O}_{2}$ at the relatively high temperatures (9). This is consistent with results found in the literature [38]:

$$
2 \mathrm{H}_{2} \mathrm{O}_{2} \longrightarrow \mathrm{H}_{2} \mathrm{O}+\mathrm{O}_{2}
$$

3.7. Mineralization Study. The complete mineralization of 1 mol MAG dye molecule implies the formation of the equivalent amount (23 moles) of $\mathrm{CO}_{2}$ at the end of the treatment. However, the depletion in TOC (shown in Figure 7) clearly indicates that the reaction does not go to completion. Extent of mineralization of the dye by Fenton-like process can be evaluated by measuring Total Organic Carbon (TOC). To determine the change in the TOC of reaction medium, initial TOC (pure dye solution) and the TOC of a sample at different intervals during the reaction were measured. TOC reduction was determined as follows:

$$
\mathrm{TOC}_{\text {removal }}=\frac{1-\mathrm{TOC}_{t}}{\mathrm{TOC}_{0}} \times 100,
$$

where $\mathrm{TOC}_{t}$ and $\mathrm{TOC}_{0}\left(\mathrm{mg} \mathrm{L}^{-1}\right)$ are values at time $(t)$ and at time (0), respectively. $70 \%$ TOC reduction is achieved for MAG dye in $30 \mathrm{~min}$. In fact, after $30 \mathrm{~min}$ of reaction,

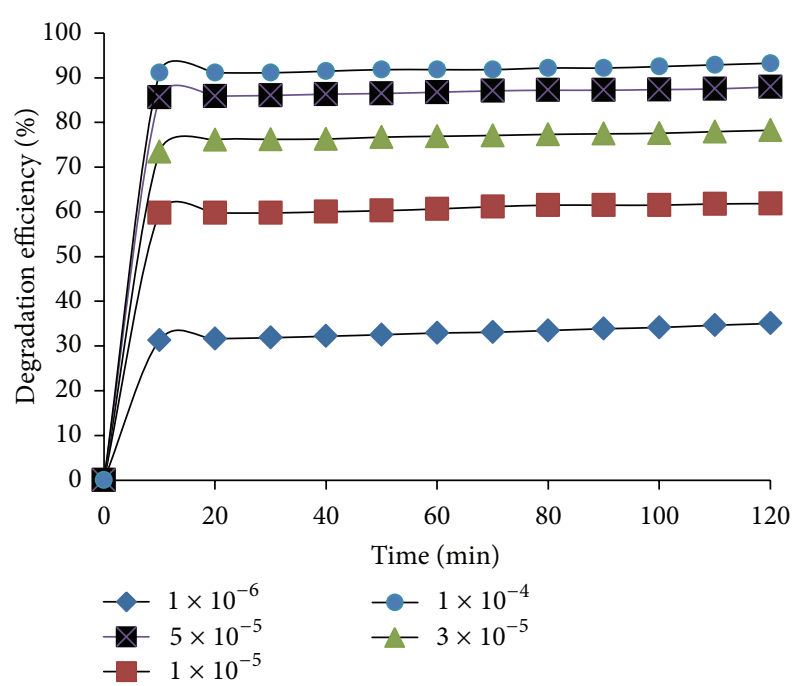

FIGURE 5: Effect of MAG concentration on the discoloration efficiency for Fenton-like oxidation process.

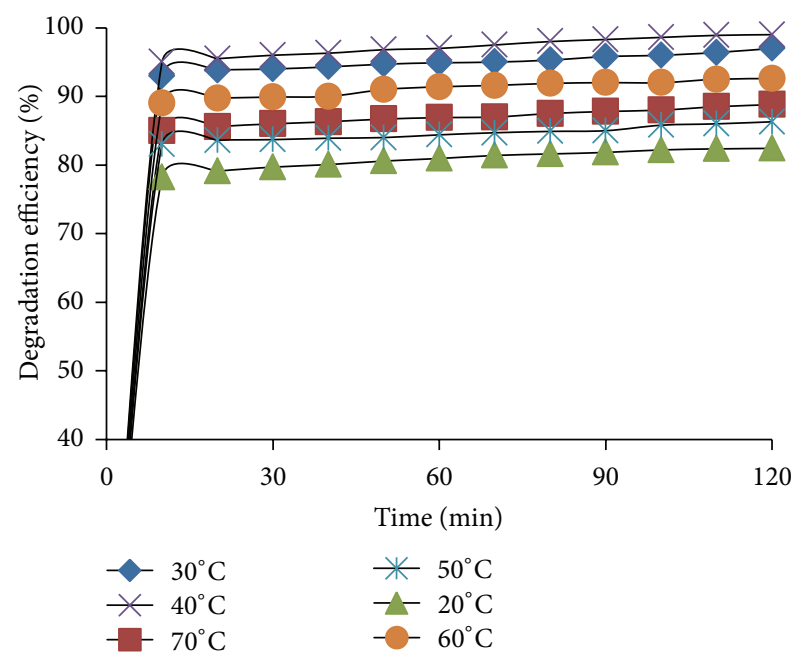

Figure 6: Effect of temperature on the discoloration efficiency for Fenton-like oxidation process.

about $70 \%$ of the initial organic carbon had been transformed into $\mathrm{CO}_{2}$, which implied the existence of other organic compounds in the solution and the partial mineralization of dyes $[39,40]$.

3.8. Effect of $\mathrm{Cl}^{-}$and $\mathrm{SO}_{4}{ }^{2-}$ on Fenton Effectiveness. $\mathrm{Cl}^{-}$ and $\mathrm{SO}_{4}{ }^{2-}$ are common coexisting anions with dyes in wastewater; therefore, the effect of $\mathrm{Cl}^{-}$and $\mathrm{SO}_{4}{ }^{2-}$ ions on $\mathrm{MAG}$ removal by Fenton-like process was investigated. It was found that the presence of $\mathrm{Cl}^{-}$at the concentration range of $0-0.1 \mathrm{~mol} \mathrm{~L}^{-1}$ did not have a significant effect on removing MAG. The effect of $\mathrm{SO}_{4}{ }^{2-}$ on the removal of MAG was significant at the concentration range of $0-0.1 \mathrm{~mol} \mathrm{~L}^{-1}$. The removal of MAG decreased at a concentration of $0.02 \mathrm{~mol} \mathrm{~L}^{-1}$ 


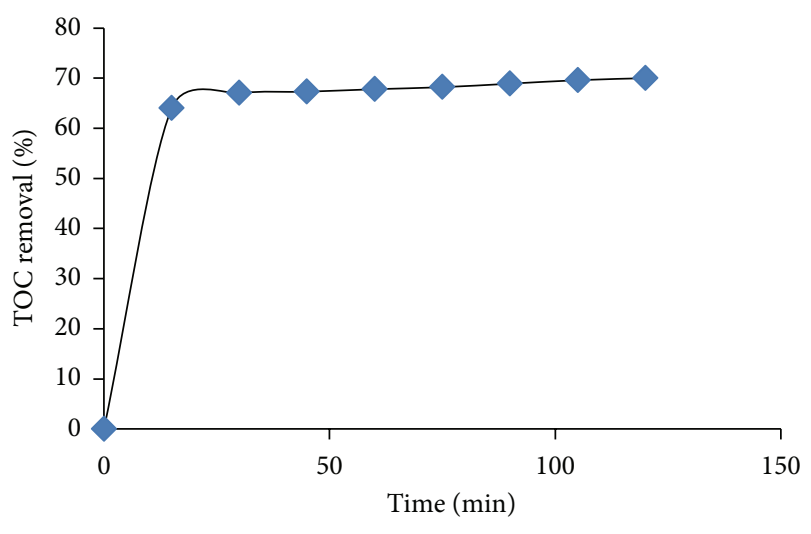

FIGURE 7: TOC removal for MAG dye by Fenton-like oxidation process.

of $\mathrm{SO}_{4}{ }^{2-}$. The removal of MAG decreased to $45 \%$ for concentration of $0.02 \mathrm{~mol} \mathrm{~L}^{-1}$ of $\mathrm{SO}_{4}{ }^{2-}$.

3.9. Kinetic of Fenton Reaction. The general elementary rate law for reaction of a target organic compound (MAG) can be written as follows:

$$
\frac{-\mathrm{d} C_{\mathrm{MAG}}}{\mathrm{d} t}=k_{\mathrm{HO}} k \cdot \mathrm{OH} k_{\mathrm{RH}}+\Sigma K_{\mathrm{oxi}} C_{\mathrm{oxi}} C_{\mathrm{RH}},
$$

where oxi represents oxidants other than ${ }^{\circ} \mathrm{OH}$ that may be present, such as ferryl, hydroxyl radical which is usually regarded as the sole or most important reactive species. Then

$$
\frac{-\mathrm{d} C_{\mathrm{MAG}}}{\mathrm{d} t}=k_{\mathrm{HO}} k_{\cdot \mathrm{OH}} k_{\mathrm{MAG}} \cdot
$$

And, by integration, the rate law of first-order reaction can be written as follows:

$$
\ln C_{\mathrm{MAG}}=\ln C_{(\mathrm{MAG}) 0}-k_{\mathrm{app}} t,
$$

where $C_{\mathrm{MAG}}$ and $C_{(\mathrm{MAG}) 0}$ are initial concentration of MAG and concentration of MAG at any time. A plot of $\ln C_{\mathrm{MAG}}$ versus time generated a straight line with a negative slope. The slope of this line corresponds to the apparent rate constant value for the degradation of the organic target compound. In our case, we follow the rate of decolourization of the MAG dye. Consequently, (13) was converted to

$$
\frac{\ln C_{\mathrm{MAG}}}{\ln C_{(\mathrm{MAG}) 0}}=-k_{\mathrm{app}} t .
$$

Figure 8 shows the plot of first-order Fenton reaction. Rate law of the second-order reaction can be written as follows:

$$
\frac{1}{\left[C_{\mathrm{MAG}}\right]}-\frac{1}{\left[C_{(\mathrm{MAG}) 0}\right]}=k t .
$$

The plot of $1 /[C]$ against $k$ shows the rate constant of second-order Fenton reaction (Figure 9). The results from $R^{2}$ of Figures 8 and 9 show that the kinetic of Fenton-like reaction for degradation of MAG was second-order reaction [41].

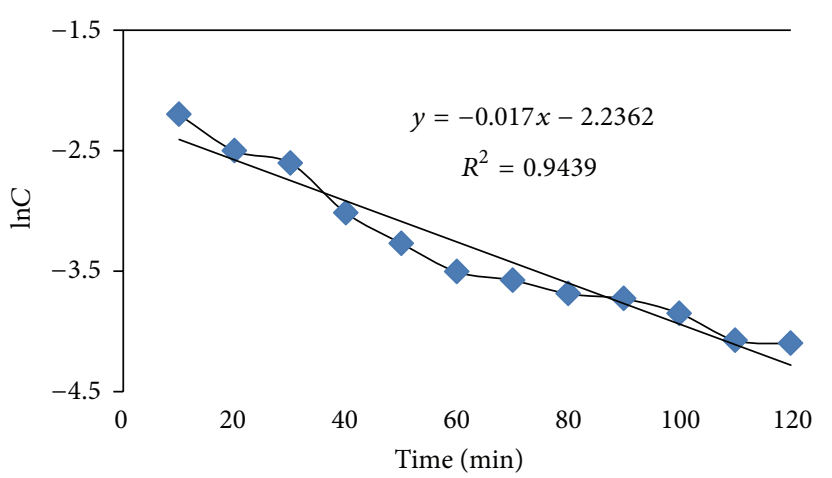

FIGURE 8: Pseudo-first-order model for Fenton-like oxidation of MAG.

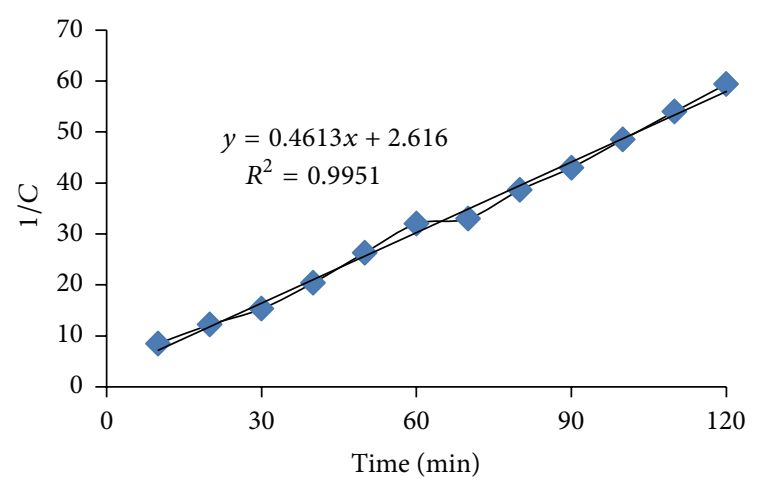

FIGURE 9: Pseudo-second-order model for Fenton-like oxidation of MAG.

3.10. Thermodynamic of Fenton Reaction. Thermodynamic parameters including Gibbs free energy $\Delta G^{\circ}$, standard enthalpy $\Delta H^{\circ}$, and standard entropy $\Delta S^{\circ}$ are the parameters to better understand the temperature effect on degradation of dye which was studied. Gibbs free energy $\Delta G^{\circ}$ by using equilibrium constant $K_{C}$ is calculated:

$$
\Delta G^{\circ}=-R T \ln K_{C}
$$

$K_{C}$ value is calculated from the following formula:

$$
K_{\mathrm{C}}=\frac{C_{\mathrm{Ae}}}{C_{\mathrm{Se}}} .
$$

$C_{\mathrm{Ae}}$ is amount of degradation dye at equilibrium and $C_{\mathrm{Se}}$ equilibrium concentration of dye at the solution.

Standard enthalpy $\Delta H^{\circ}$ and standard entropy $\Delta S^{\circ}$ are as van't Hoff equation:

$$
\ln K_{C}=\frac{-\Delta H^{\circ}}{R T}+\frac{\Delta S^{\circ}}{R}
$$

In this equation $R$ is the gas constant equal to the public (8.314 $\mathrm{J} \mathrm{mol}^{-1} \mathrm{k}^{-1}$ ). The amounts of degradation dye at equilibrium at different temperatures $25-55^{\circ} \mathrm{C}$ have been examined to obtain thermodynamic parameters for Fentonlike reaction of MAG. $\Delta H^{\circ}$ and $\Delta S^{\circ}$ were calculated as the slope and intercept of van't Hoff plots of $\ln K_{C}$ versus 
TABLE 1: Thermodynamic parameters for Fenton oxidation of MAG $\left([\mathrm{MAG}]=3.0 \times 10^{-5} \mathrm{M},\left[\mathrm{Fe}^{3+}\right]=1.0 \times 10^{-4} \mathrm{M},\left[\mathrm{H}_{2} \mathrm{O}_{2}\right]=5.0 \times 10^{-2} \mathrm{M}\right)$.

\begin{tabular}{lccccc}
\hline $\begin{array}{l}\Delta S^{\circ} \\
\left(\mathrm{J} \mathrm{mol}^{-1} \mathrm{k}^{-1}\right)\end{array}$ & $\begin{array}{c}\Delta H^{\circ} \\
\left(\mathrm{J} \mathrm{mol}^{-1}\right)\end{array}$ & $\begin{array}{c}\Delta G^{\circ} \\
\left(\mathrm{KJ} \mathrm{mol}^{-1}\right)\end{array}$ & $K_{\mathrm{C}}$ & $T(\mathrm{~K})$ & \\
\hline \multirow{4}{*}{43.2823} & & -3.255 & 3.80 & 293 & Fenton \\
& \multirow{3}{*}{9.610} & -3.408 & 3.870 & 303 & like \\
& & -4.213 & 4.80 & 323 & oxidation \\
& & -5.680 & 7.33 & 333 & \\
\hline
\end{tabular}

$1 / T$. The results of thermodynamic parameters are given in Table 1. As observed in Table 1, negative value of $\Delta G^{\circ}$ at different temperatures shows the oxidation process to be spontaneous. The $\Delta H^{\circ}$ positive value indicates that the uptake is endothermic [42].

\section{Conclusion}

The results of Fenton-like oxidation process of MAG showed the following.

(1) The optimal parameters for Fenton-like process are

$$
\begin{gathered}
{[\mathrm{MAG}]=3 \times 10^{-5} \mathrm{M}, \quad\left[\mathrm{Fe}^{3+}\right]=1.0 \times 10^{-3} \mathrm{M},} \\
{\left[\mathrm{H}_{2} \mathrm{O}_{2}\right]=5 \times 10^{-2} \mathrm{M}, \quad \mathrm{pH}=3 .}
\end{gathered}
$$

(2) Fenton-like process not only completes decolorization of MAG dye (95\%) but also mineralizes it (70\%).

(3) The oxidation process of MAG follows pseudosecond-order kinetic model.

(4) The negative values of $\Delta G^{\circ}$ and positive value of $\Delta H^{\circ}$ obtained indicated that the MAG dye oxidation by Fenton reaction processes is spontaneous and endothermic.

(5) The overall equation of MAG degradation and production of carbon dioxide and nitrate ion is as follows:

$$
\begin{gathered}
\mathrm{C}_{23} \mathrm{H}_{25} \mathrm{ClN}_{2}+52 \mathrm{H}_{2} \mathrm{O} \longrightarrow 23 \mathrm{CO}_{2}+129 \mathrm{H}^{+} \\
+2 \mathrm{NO}_{3}{ }^{-}+\mathrm{Cl}^{-}+126 \mathrm{e}^{-}
\end{gathered}
$$

\section{References}

[1] A. Wang, J. Qu, J. Ru, H. Liu, and J. Ge, "Mineralization of an azo dye Acid Red 14 by electro-Fenton's reagent using an activated carbon fiber cathode," Dyes and Pigments, vol. 65, no. 3, pp. 227233, 2005.

[2] J. Pierce, "Colour in textile effluents-the origins of the problem," Journal of the Society of Dyers \& Colourists, vol. 110, no. 4, pp. 131-133, 1994.

[3] C. Galindo, P. Jacques, and A. Kalt, "Photochemical and photocatalytic degradation of an indigoid dye: a case study of acid blue 74 (AB74)," Journal of Photochemistry and Photobiology A, vol. 141, no. 1, pp. 47-56, 2001.

[4] M. Muthukumar and N. Selvakumar, "Studies on the effect of inorganic salts on decolouration of acid dye effluents by ozonation," Dyes and Pigments, vol. 62, no. 3, pp. 221-228, 2004.
[5] R. Sabry, A. Hafez, M. Khedr, and A. El-Hassanin, "Removal of lead by an emulsion liquid membrane. Part I," Desalination, vol. 212, no. 1-3, pp. 165-175, 2007.

[6] P. K. Malik and S. K. Saha, "Oxidation of direct dyes with hydrogen peroxide using ferrous ion as catalyst," Separation and Purification Technology, vol. 31, no. 3, pp. 241-250, 2003.

[7] E. E. Ebrahiem, M. N. Al-Maghrabi, and A. R. Mobarki, "Removal of organic pollutants from industrial wastewater by applying photo-Fenton oxidation technology," Arabian Journal of Chemistry. In press.

[8] I. Fatimah, S. Wang, and D. Wulandari, “ $\mathrm{ZnO} /$ montmorillonite for photocatalytic and photochemical degradation of methylene blue," Applied Clay Science, vol. 53, no. 4, pp. 553-560, 2011.

[9] S. Hashemian, " $\mathrm{MnFe}_{2} \mathrm{O}_{4}$ /bentonite nano composite as a novel magnetic material for adsorption of acid red 138," African Journal of Biotechnology, vol. 9, no. 50, pp. 8667-8671, 2010.

[10] S. Hashemian, "Removal of acid red 151 from water by adsorption onto nano-composite $\mathrm{MnFe}_{2} \mathrm{O}_{4}$ /kaolin," Main Group Chemistry, vol. 10, no. 2, pp. 105-114, 2011.

[11] S. Hashemian, "Study of adsorption of acid dye from aqueous solutions using bentonite," Main Group Chemistry, vol. 6, pp. 97-107, 2007.

[12] S. Hashemian and M. Salimi, "Nano composite a potential low cost adsorbent for removal of cyanine acid," Chemical Engineering Journal, vol. 188, pp. 57-63, 2012.

[13] S. Hashemian and M. Mirshamsi, "Kinetic and thermodynamic of adsorption of 2-picoline by sawdust from aqueous solution," Journal of Industrial and Engineering Chemistry, vol. 1, pp. 20102015, 2012.

[14] A. R. Khataee, V. Vatanpour, and A. R. Amani Ghadim, "Decolorization of C.I. Acid Blue 9 solution by UV/Nano$\mathrm{TiO}_{2}$, Fenton, Fenton-like, electro-Fenton and electrocoagulation processes: a comparative study," Journal of Hazardous Materials, vol. 161, no. 2-3, pp. 1225-1233, 2009.

[15] J. Ma, W. Song, C. Chen, W. Ma, J. Zhao, and Y. Tang, "Fenton degradation of organic compounds promoted by dyes under visible irradiation," Environmental Science and Technology, vol. 39, no. 15, pp. 5810-5815, 2005.

[16] F. Chen, W. Ma, J. He, and J. Zhao, "Fenton degradation of malachite green catalyzed by aromatic additives," Journal of Physical Chemistry A, vol. 106, no. 41, pp. 9485-9490, 2002.

[17] M. S. Lucas and J. A. Peres, "Decolorization of the azo dye reactive black 5 by Fenton and Photo-Fenton oxidation," Dyes and Pigments, vol. 71, no. 3, pp. 236-244, 2006.

[18] W.-P. Ting, M.-C. Lu, and Y.-H. Huang, "Kinetics of 2,6dimethylaniline degradation by electro-Fenton process," Journal of Hazardous Materials, vol. 161, no. 2-3, pp. 1484-1490, 2009.

[19] H.-J. Fan, S.-T. Huang, W.-H. Chung, J.-L. Jan, W.-Y. Lin, and C.C. Chen, "Degradation pathways of crystal violet by Fenton and Fenton-like systems: condition optimization and intermediate separation and identification," Journal of Hazardous Materials, vol. 171, no. 1-3, pp. 1032-1044, 2009.

[20] E. Neyens and J. Baeyens, "A review of classic Fenton's peroxidation as an advanced oxidation technique," Journal of Hazardous Materials, vol. 98, no. 1-3, pp. 33-50, 2003.

[21] C. Bouasla, M. E.-H. Samar, and F. Ismail, "Degradation of methyl violet 6B dye by the Fenton process," Desalination, vol. 254, no. 1-3, pp. 35-41, 2010.

[22] N. Masomboon, C. Ratanatamskul, and M.-C. Lu, "Kinetics of 2,6-dimethylaniline oxidation by various Fenton processes," Journal of Hazardous Materials, vol. 192, no. 1, pp. 347-353, 2011. 
[23] M. H. Baek, C. O. IJagbemi, and D. S. Kim, "Spectroscopic studies on the oxidative decomposition of malachite green using ozone," Water Science and Technology, vol. 62, no. 6, pp. 13041311, 2010.

[24] H. Zheng, H. Zhang, X. Sun, P. Zhang, T. Tshukudu, and G. Zhu, "The catalytic oxidation of malachite green by the microwaveFenton processes," Dyes Pigments, vol. 62, no. 1, pp. 1-10, 2004.

[25] P. A. Soloman, C. A. Basha, M. Velan, and N. Balasubramanian, "Electro oxidation of malachite green and modeling using ANN," Chemical and Biochemical Engineering Quarterly, vol. 24, no. 4, pp. 445-452, 2010.

[26] V. K. Garg, R. Kumar, and R. Gupta, "Removal of malachite green dye from aqueous solution by adsorption using agroindustry waste: a case study of Prosopis cineraria," Dyes and Pigments, vol. 62, no. 1, pp. 1-10, 2004.

[27] T. Santhi and S. Manonmani, "Malachite green removal from aqueous solution by the peel of Cucumis sativa fruit," CleanSoil, Air, Water, vol. 39, no. 2, pp. 162-170, 2011.

[28] S. P. S. Syed, "Study of the removal of malachite green from aqueous solution by using solid agricultural waste," Research Journal of Chemical Sciences, vol. 881, no. 1, pp. 88-104, 2011.

[29] G. H. Sonawanea and V. S. Shrivastava, "Kinetics of decolourization of malachite green from aqueous medium by maize cob (Zea maize): an agricultural solid waste," Desalination, vol. 250, pp. 94-105, 2009.

[30] B. Ensing, F. Buda, and E. J. Baerends, "Fenton-like chemistry in water: oxidation catalysis by $\mathrm{Fe}(\mathrm{III})$ and $\mathrm{H}_{2} \mathrm{O}_{2}$," Journal of Physical Chemistry A, vol. 107, no. 30, pp. 5722-5731, 2003.

[31] M. Neamtu, A. Yediler, I. Siminiceanu, and A. Kettrup, "Oxidation of commercial reactive azo dye aqueous solutions by the photo-Fenton and Fenton-like processes," Journal of Photochemistry and Photobiology A, vol. 161, no. 1, pp. 87-93, 2003.

[32] M. Pérez, F. Torrades, X. Domènech, and J. Peral, "Fenton and photo-Fenton oxidation of textile effluents," Water Research, vol. 36, no. 11, pp. 2703-2710, 2002.

[33] J.-H. Sun, S.-P. Sun, G.-L. Wang, and L.-P. Qiao, "Degradation of azo dye Amido black 10B in aqueous solution by Fenton oxidation process," Dyes and Pigments, vol. 74, no. 3, pp. 647$652,2007$.

[34] D. R. de Souza, E. T. F. Mendonça Duarte, G. de Souza Girardi et al., "Study of kinetic parameters related to the degradation of an industrial effluent using Fenton-like reactions," Journal of Photochemistry and Photobiology A, vol. 179, no. 3, pp. 269-275, 2006.

[35] M. L. Kremer, "Complex versus "Free Radical" mechanism for the catalytic decomposition of $\mathrm{H}_{2} \mathrm{O}_{2}$ by $\mathrm{Fe}^{3+}$," International Journal of Chemical Kinetics, vol. 17, pp. 1299-1314, 1985.

[36] H. Hassan and B. H. Hameed, "Fenton-like oxidation of acid red 1 solutions using heterogeneous catalyst based on ball clay," International Journal of Environmental Science, vol. 2, no. 3, pp. $1-5,2011$.

[37] H.-Y. Xu, M. Prasad, and Y. Liu, "Schorl: a novel catalyst in mineral-catalyzed Fenton-like system for dyeing wastewater discoloration," Journal of Hazardous Materials, vol. 165, no. 13, pp. 1186-1192, 2009.

[38] G. R. Mahdavinia and R. Zhalebaghy, "Removal kinetic of cationic dye using poly (sodium acrylate)-carrageenan/Namontmorillonite nanocomposite superabsorbents," Journal of Materials and Environmental Science, vol. 3, no. 5, pp. 895-906, 2012.
[39] S. Hashemian, M. Tabatabaee, and M. Gafari, "Fenton oxidation of methyl violet in aqueous solution," Journal of Chemistry, vol. 2013, Article ID 509097, 6 pages, 2013.

[40] J. J. Pignatello, E. Oliveros, and A. MacKay, "Advanced oxidation processes for organic contaminant destruction based on the fenton reaction and related chemistry," Critical Reviews in Environmental Science and Technology, vol. 36, no. 1, pp. 1-84, 2006.

[41] G. E. A. Mahmoud and L. F. M. Ismail, "Factors affecting the kinetic parameters related to the degradation of direct yellow 50 by Fenton and Photo-Fenton Processes," Journal of Basic and Applied Chemistry, vol. 1, no. 8, pp. 70-79, 2011.

[42] L. Núñez, J. A. García-Hortal, and F. Torrades, "Study of kinetic parameters related to the decolourization and mineralization of reactive dyes from textile dyeing using Fenton and photoFenton processes," Dyes and Pigments, vol. 75, no. 3, pp. 647$652,2007$. 

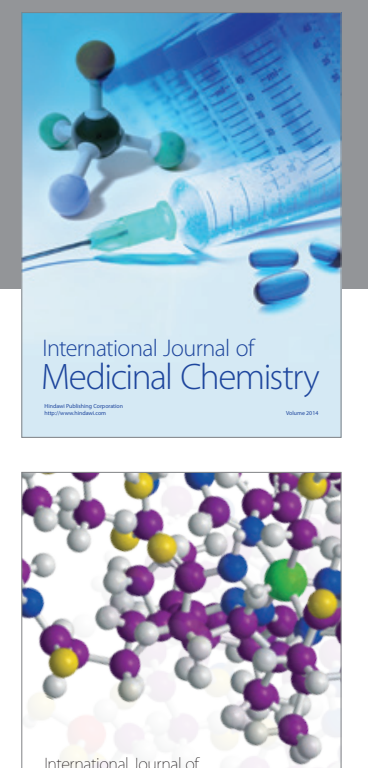

\section{Carbohydrate} Chemistry

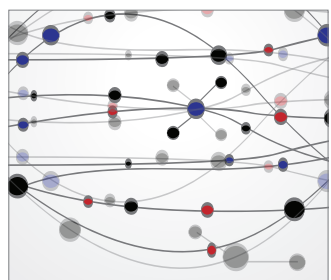

The Scientific World Journal
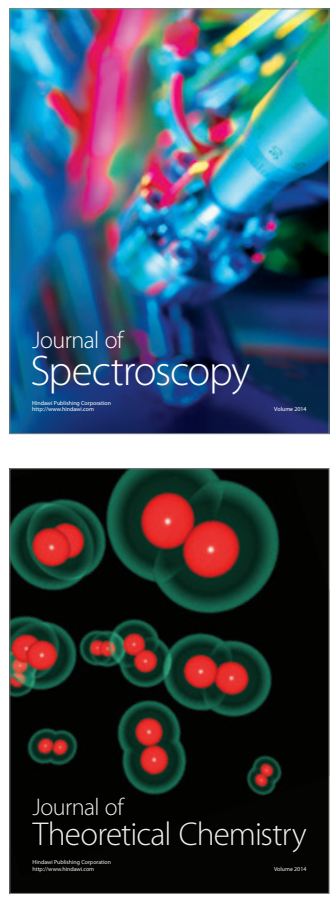
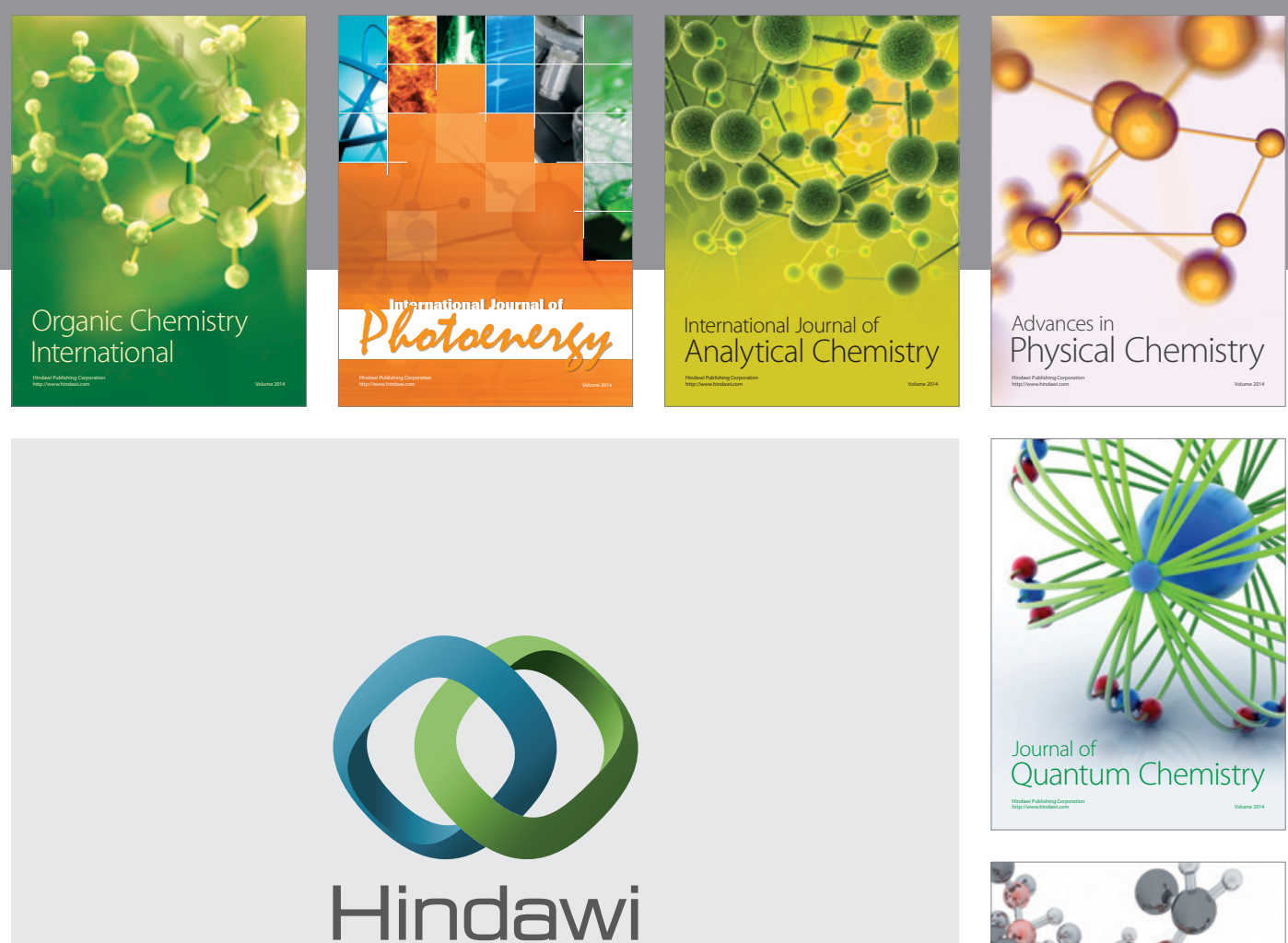

Submit your manuscripts at

http://www.hindawi.com

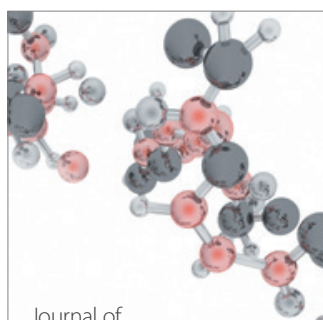

Analytical Methods

in Chemistry

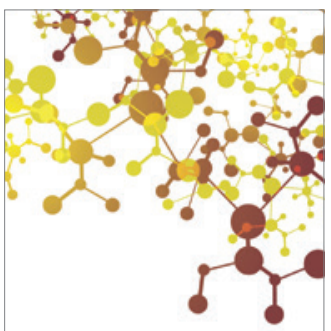

Journal of

Applied Chemistry

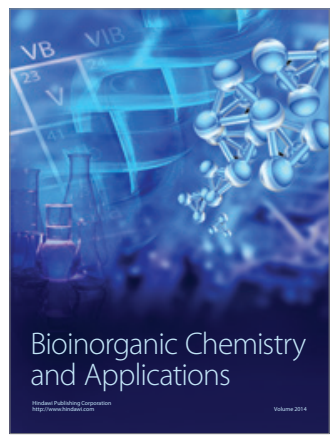

Inorganic Chemistry
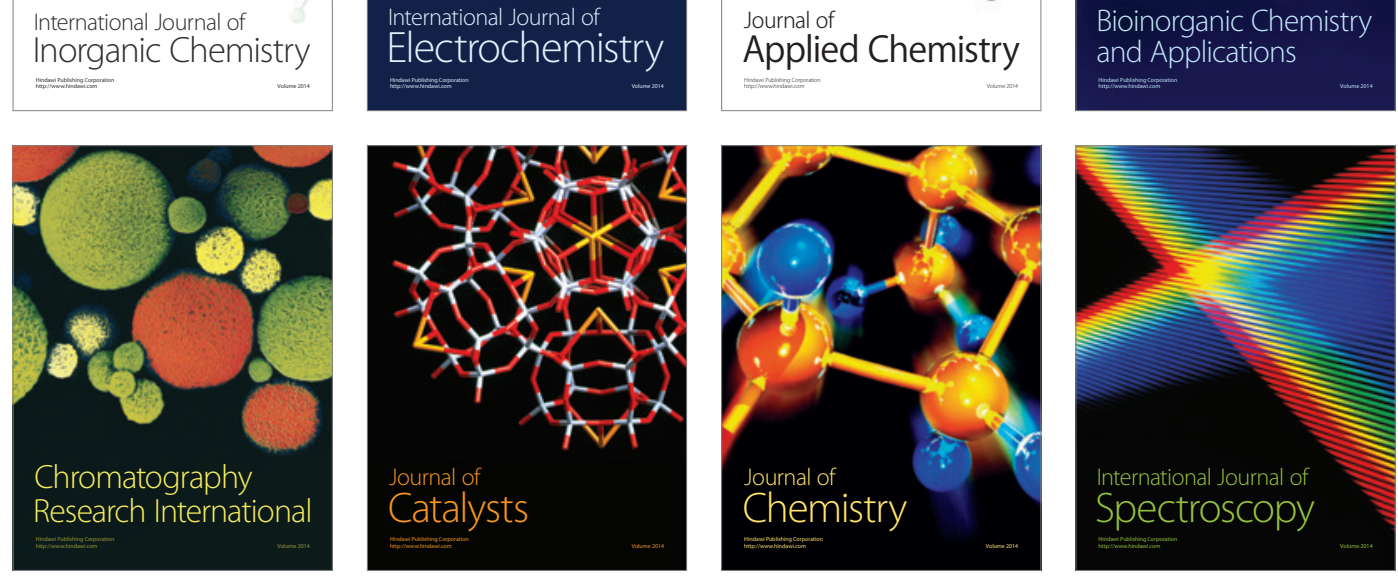